УДК 796
https://doi.org/10.36906/FKS-2021/77

Пашута В.Л., д-р пед. наук;

Ларькин А.И., канд. истор. наук

Военный институт физической культурь,

г. Санкт-Петербург, Россия

\title{
ВЛИЯНИЕ ФИЗИЧЕСКОЙ КУЛЬТУРЫ НА ПРОЦЕССЫ СТАНОВЛЕНИЯ МОЛОДОГО ПОКОЛЕНИЯ СОВРЕМЕННОЙ РОССИИ
}

Аннотация. В статье рассматриваются некоторые аспекты влияния физической культуры и спорта, физического воспитания на влияние физической культуры на процессы становления молодого поколения современной России.

Ключевые слова: физическая культура, физическое воспитание, становление личности.

Pashuta V.L., Ph.D.;

Larkin A.I., Ph.D.

Military Institute of Physical Culture,

St. Petersburg, Russia

\section{THE INFLUENCE OF PHYSICAL CULTURE ON THE PROCESSES OF FORMATION OF THE YOUNG GENERATION OF MODERN RUSSIA}

Annotation. The article deals with some aspects of the influence of physical culture and sports, physical education on the processes of format on of the young generation of modern Russia.

Keyword: physical culture, physical education, personal development

Утверждается, что прямой связи между физическим и, например, духовным, социальным развитием человека нет. Специальными исследованиями ученых, а также и сама практика занятий физическим развитием и совершенствованием человека в любом возрасте, что предполагает одновременно и воспитательный эффект в этом процессе, подтверждается, что совмещение этих факторов в единый процесс способствует, особенно детям и молодым поколениям, умственному, духовному развитию тех, кто занимается физической культурой и спортом. В подтверждение данной мысли можно назвать исследования профессора Якутского университета И.И. Портнягина, в которых достаточно убедительно показана взаимосвязь духовного, социального и физического развития (например, материалы из 2-й главы докторской диссертации 2000 г. «Научно-педагогические основы интеллектуального развития школьников-спортсменов...») [10]. Несомненно, что сам по себе образовательный процесс, в широком смысле слова, способствует усвоению специальных знаний, в том числе и из области физкультурно-спортивной деятельности, а, значит, помогает развитию многих качеств человека. Это происходит в результате применения известных в науке методов: рассуждение, наблюдение и сравнение, анализ, опрос, обобщение и критическая оценка.

Разумеется, что связь умственного воспитания с физическим сложна и многообразна. На занятиях по физической культуре (при правильной организации учебного процесса) занимающимся сообщаются общие сведения по истории физической культуры и спорта, необходимости, характера и особенностей развития физического воспитания, методике организации и проведения состязаний, некоторым медицинским аспектам, важности 
соблюдения гигиены и т. п. Все это помогает расширять и разносторонний кругозор всех обучающихся на занятиях по физической культуре.

Несомненно, что физическое воспитание положительно влияет на работоспособность при всех видах труда: умственного, духовного, физического. Поэтому в режим рабочего дня, особенно для людей умственного труда, необходимо включение элементов активного отдыха, периодически проводимые разнообразные физические упражнения. Эти упражнения, как качественно иной вид деятельности, дают возможность наиболее рационально и более продуктивно организовать таким людям работу умственного свойства. Это необходимо и детям школьного возраста, много времени занимающихся на уроках умственной деятельностью. Доказано, что физическое воспитание с элементами физических упражнений играет заметную роль в повышении умственной работоспособности, под которой понимается способность противостоять неблагоприятному влиянию нервных перегрузок. Хорошо известно, что освоение современных учебных программ сопряжено с перенесением значительных нервно-психических напряжений. Поэтому определенный уровень физической подготовленности способствует обеспечению необходимой устойчивости умственной работоспособности. Таким образом, само физическое здоровье, укрепляемое через влияние физического воспитания, есть важнейшая предпосылка для всех видов полноценной деятельности.

Приобретаемые качества, сформированные в том числе и в результате спортивной деятельности под непосредственным педагогическим руководством, формируют затем способность к самосознательному проявлению и в других видах жизнедеятельности человека. Знание вскрытых закономерностей позволяет, как утверждает профессор И.И. Портнягин, управлять процессом воспитания личности школьников также и в спортивной деятельности $[10$, c. 30$]$.

Специальными исследованиями, проведенными видными исследователями в этой области: Б.А. Ашмариным (напр., в части 1-й учебника «Теория и методики физического воспитания», гл. 4, 5 рассказывающих о роли физкультурной учебной деятельности в нравственном воспитании) [1; 13]; М.Я. Виленским и А.Г.Горшковым (в учебнике «Физическая культура»: гл. «Физическая культура в общекультурной и профессиональной подготовке студентов») [15]; А.П. Матвеевым (в Пособии для учителей «Физическая культура. Рабочие программы...»: раздел «Ценностные ориентиры содержания учебного предмета») [8], И.И. Портнягиным (в работе «Активизация учебно-познавательной деятельности школьников в процессе физического воспитания») [11]; Н.И. Пономаревым в книге «Социальные функции физической культуры и спорта» [14]; В.П. Филиным (в ряде книг содержатся сведения о влиянии физического воспитания на эмоционально-умственную деятельность молодого поколения) [16; 17]; Н.К. Шамаевым (докторская диссертация «Теория и практика нравственного развития личности подростка в процессе физического воспитания с этнокультурной направленностью», а также книга «Нравственное развитие школьников в процессе традиционного физического воспитания» $[19 ; 20]$ и др.)установлено, что в системе «состояние организма - физическая нагрузка - умственная работоспособность» конечный результат при различных ее звеньях оказывается неодинаковым.

Исследователи выявили несколько проявлений этой взаимосвязи. Как утверждает Вайнбаум Я.С. в ряде работ (в частности, «Дозирование физических нагрузок школьников», изданной в серии «Библиотека учителя физической культуры») различная по величине нагрузка при разных состояниях организма воздействует на умственную работоспособность учащихся следующим образом: а) при нормальном физическом состоянии (какое наблюдается у большинства школьников-спортсменов) частота сердечных сокращений (ЧСС) сказывается 
трояко: низкая (равная 120-130 уд/мин) - индифферентно; средняя (от 150 до 180 уд/мин) стимулирующее; высокая (свыше 180 уд/мин) - угнетающе; б)при ослабленном состоянии (напр., из-за перенесенной болезни, нарушения режима питания и сна, возможно утомленного состояния, а также низкой физической тренированности), которое может возникать у любого подростка в тот или иной период, стимулирующее значение имеет нагрузка до 140 уд/мин; более высокая ведет, как правило, только к снижению показателей умственной работоспособности), когда физическое состояние находится на высоком уровне (хорошая спортивная форма), почти любая нагрузка не оказывает отрицательного воздействия на устойчивость умственной работоспособности [3, с. 39-40]. И как утверждают исследователи, учет этих особенностей воздействия нагрузки позволит обучаемым иметь возможность после тренировки отправиться на занятие с высокой умственной работоспособностью.

В трудах Г.И. Щукиной («Проблема познавательного интереса в педагогике») [21], В.Б. Бондаревского («Воспитание интереса к знаниям и потребности к самообразованию») [2], И.Я. Лернера («Дидактические основы методов обучения») [6] и многих других, подтверждается, что процесс формирования познавательных интересов происходит в сфере деятельности. Хорошо известно, что главный вид деятельности детей - учение, в процессе которого происходит систематическое овладение знаниями из различных предметных областей, происходит процесс приобретения и совершенствования способов (т. е. умений и навыков) познавательной деятельности, формирование целей и т. п.

Как свидетельствует анализ многочисленной спортивно-педагогической литературы российских авторов, физическое воспитание серьезно способствует решению задач по формированию личности, воспитанию воли, многих позитивных качеств, характера, эмоций, эстетических потребностей личности. Возможно впервые о существовании индивидуальных различий в умственных (интеллектуальных) способностях человека начал говорить английский ученый, психолог Фрэнсис Гальтон (1822-1911). В своем основном труде «Исследование человеческих способностей и их развитие» (1883 г.) он отождествлял интеллект врожденными психофизиологическими функциями, такими как ощущение, эмоция, реакция и т.п. В 1905 г. французские ученые, крупные специалисты в области психологии А. Бине (1857-1911) и Т. Симон (1873-1961) разработали первый практический психологический тест, используемый для диагностики детей с задержкой умственного развития, и который называют «шкалой умственного развития Бине-Симона» (аналог современного IQ-теста). Применение серии тестов из 30 и более заданий давало возможность различать детей на способных и неспособных. Это помогало в какой-то мере определить нечто вроде уровня способностей человека.

В отечественной психологии интеллект рассматривается как компонент индивидуальности, связанный с личностными характеристиками (исследования связей интеллекта с эмоционально-волевыми особенностями, социально-экономическими условиями и т. д.). Отечественный психолог, основатель национальной школы дифференциальной психологии Б.М. Теплов (1896-1965) утверждал, что «...способность есть индивидуальное свойство, которое различно проявляется у разных людей. Это переменная. Ее можно измерять. Способность есть свойство, связанное с успешным освоением/ осуществлением деятельности. Это успех. Его можно измерять...» [12, с. 9-10].

Действительно, интеллект многие ученые рассматривают как сложную многоуровневую систему. Большой вклад в развитие этого вопроса внесла, например, крупный специалист в области психологии, доктор психологических наук, профессор М.А. Холодная в своей книге «Психология интеллекта: парадоксы исследования» [18]. Среди многих понятий интеллекта обычно выделяются наиболее важные: 1) интеллект как результат процесса социализации, а 
также влияния культуры в целом (социокультурный подход); 2) интеллект как следствие адаптации к требованиям окружающей среды в естественных условиях взаимодействия человека с окружающим миром (генетический подход); 3) интеллект как особая форма человеческой деятельности (процессуально-деятельностный подход); 4) интеллект как продукт целенаправленного обучения и т. д.

Например, в кандидатской диссертации Овсянниковой О.Н. «Психолого-педагогические условия развития креативных способностей у курсантов военного вуза» (2005 г.) утверждается, что интеллектуальные силы мобилизуются, когда в процессе занятий с применением физических упражнений обучающимся объясняются отдельные движения тела с точки зрения анатомии и физиологии человека обеспечивается раскрытие анатомических и физиологических основ физического воспитания: знания по топографии скелетных мышц и их функций связываются с анализом техники физических упражнений. Также спортивные достижения во многом объясняются при анализе деятельности основных физиологических систем организма спортсмена и т. п. [9].

На основе изученной литературы можно определить систему мероприятий по регулированию состояния умственной работоспособности обучающихся. Она включает в себя: 1) целенаправленное повышение уровня развития двигательных качеств; 2) обеспечение непрерывности физической нагрузки на организм учащихся в течение всего периода обучения; 3) учет физического состояния их организма и соответственное регулирование в процессе физической нагрузки; 4) создание положительного эмоционального фона и его регулирование в процессе физической тренировки; 5) обеспечение благоприятных условий для деятельности высшего отдела центральной нервной системы - коры головного мозга, которая обусловливает состояние умственной работоспособности.

Регулярные занятия физической культурой и спортом, участие в спортивных соревнованиях помогают своевременно «перестроить» центральную нервную систему обучающихся с одного вида деятельности на другой, способствуют укреплению здоровья, улучшают не только физические, но и психологические качества, повышают умственную работоспособность. Подтвердим высказывания исследователей, что время, затраченное на тренировки и соревнования, полностью возмещается высокой работоспособностью при усвоении изучаемых дисциплин другой направленности. Также экспериментально выявлено, что физически более развитые воспитанники подходят к другим занятиям более свежими и настроенными, в отличие от тех, которые не занимаются физической культурой и спортом, легче переносят нервные нагрузки, например, во время экзаменационных сессий и т. п.

О связи физического и умственного развития было в свое время сказано крупным отечественным ученым в области биологии, медицины, физического воспитания, педагогом Петром Францевичем Лесгафтом, который указывал на творческий, интеллектуальный характер деятельности личности при занятиях физическими упражнениями: «Путем анализа и сравнения, получаемые извне впечатления переходят в умственную работу, появляясь уже затем в виде отвлеченных понятий. Соответственно этому следует научиться анализировать и сравнивать движения, стараясь приспособить их к такой активной деятельности, в которой наибольшая работа проводилась бы при наименьшей затрате труда, что возможно также и при отвлеченных умственных занятиях» [5, с. 171].

Итак, регулярные занятия физической культурой, участие в спортивных соревнованиях не только помогают своевременно переключить центральную нервную систему обучающихся с одного вида деятельности на другой, укрепляют здоровье, улучшают психофизические качества, повышают умственную работоспособность, но также способствуют развитию общего мировоззрения человека. Например, основными свойствами и качествами 
мировоззрения воспитанников суворовских военных училищ, курсантов военных учебных заведений являются его целостность, убежденность, его связь с деятельностью и поведением. Известно, что целостность, устойчивость мировоззрения определяется не только «набором» соответствующих взглядов и убеждений, но их «прочностью», когда понимание и убеждения по конкретным вопросам как бы «согласуются» между собой и составляют «единую систему» мнений.

Для более успешного развития креативных способностей у обучающихся в рамках современных технологий обучения используют методы развивающего и проблемного обучения: проблемный, частично-поисковый (эвристический), исследовательский, деловые игры. Это объясняется тем, что в них, как правило, преобладает продуктивнопреобразовательная деятельность обучающихся.

По мнению диссертанта В.Н. Власова, занимавшегося исследованиями методики бега у обучающихся, в игре развивается продуктивное творческое поисковое мышление воспитанников не вообще, а применительно к выполнению будущих должностных обязанностей и функций. В ходе игры имеется возможность отменить решение, которое оказалось неудачным, вернуться назад и принять другой ряд решений, для того чтобы определить их преимущества и недостатки по сравнению с уже опробованными. При этом одна и та же игровая ситуация может проигрываться несколько раз для того, чтобы дать возможность обучающимся побывать в разных ролях и, если это необходимо, предложить свои решения [4].

Целенаправленное формирование устойчивой мотивации деятельности, психологической установки на творчество является неотъемлемой частью развития креативных способностей обучающихся, в том числе обучающихся в военных учебных заведениях. Названный нами выше известный ученый в отечественной педагогической науке И.Я. Лернер (1917-1996) полагал, что определение требуемых уровней усвоения изучаемого материала и их правильное задание помогают преподавателю обеспечить в конечном результате подготовку военного специалиста-профессионала с гарантированным качеством обучения. Помимо этого, появляется возможность дифференцировать знания, необходимые воспитанникам, с целью создания соответствующих тестов и тестовых заданий для контроля качества их усвоения [6].

Известно, что в педагогической науке важным этапом проектирования и конструирования технологии обучения, от которого зависит результативность всего дидактического процесса, является этап целеполагания, заключающийся в постановке и определении целей обучения. Под результативностью этого процесса понимается достижение обучающимися этих целей, которые заключены в систему наиболее значимых профессиональных умений и навыков, т.е. те умения и навыки, которые должны быть сформированы у выпускника вуза. Целеполагание всегда рассматривалось как важнейшая категориальная характеристика дидактического процесса. Исследованию этой проблемы уделяли особое внимание многие ученые-педагоги, такие как Ю.К. Бабанский, В.П. Беспалько, Т.А. Ильина, В.В. Краевский, П.И. Образцов, В.А. Сластенин и некоторые другие. Тем не менее, как показала практика, степень научной разработки данной проблемы и, особенно, ее современное состояние, может быть квалифицирована как сложная и противоречивая, ввиду значительного разнообразия имеющих место сейчас подходов к ее решению. В качестве его основного преимущества выделяют возможность «совершенствовать» реальную деятельность специалиста в модель его подготовки, то есть пытаться выявлять систему умений и навыков, которыми должны овладеть обучающиеся. 
В условиях глубоких преобразований происходящих, например, в армии, когда необходим высокий уровень творческих умений офицера качественно реализовать свои способности в функциональной служебной деятельности, целевая вузовская подготовка военного специалиста должна, прежде всего, обеспечивать креативные способности личности, ее активное владение ведущими способами и инструментальными умениями: оперативного и точного отбора необходимой информации; генерирования идей и решения проблемных задач в нестандартных условиях военной службы; методикой решения изобретательских задач в военно-технической деятельности и др. [7].

В заключение можно сказать, что физическая культура и спорт, активная учебная, профессиональная деятельность с некоторыми элементами физической активности, способствуют повышению умственной работы, формированию интеллектуальной способности каждого человека, его умению объяснить, обобщить, проанализировать какиелибо ситуации, например, события политической жизни и т. п. Занятия физкультурой, спортом способствуют развитию не только физических сил человека, но и осознанию значимости оздоровительной нагрузки, и, кроме этого, повышению научного мировоззрения, гражданственности и общей культуры молодого человека. Такой человек, с малых лет занимающийся физкультурой и спортом, ведущий активный образ жизни, не только совершенствует свои физические возможности, но также способствует формированию таких качеств, присущие личности с большой буквы, как высокая нравственность, творческая активность, гражданская смелость и воля, критическое отношение к антиобщественным проявлениям со стороны кого-либо. Поэтому, все те положительные качества и свойства, которые человек приобрел, активно занимаясь физкультурной деятельностью и спортом, формируют его как личность, которая обладает высоким уровнем общечеловеческой культуры.

\section{Литература}

1. Ашмарин Б.А. Теория и методика педагогических исследований в физическом воспитании. М.: Физкультура и спорт, 1978. 223 с.

2. Бондаревский В.Б. Воспитание интереса к знаниям и потребности к самообразованию: книга для учителя. М.: Просвещение, 1985. 141 с.

3. Вайнбаум Я.С. Дозирование физических нагрузок школьников. М.: Просвещение, 1991.64 c.

4. Власов В.Н. Экспериментальное исследование методики воспитания быстроты и скорости бега у детей младшего и среднего школьного возраста: Автореф. дис. ... канд. пед. наук. М., 1971. 22 с.

5. Лесгафт П.Ф. Задачи физического развития в школе // Здоровье человека, теория и методика физической культуры и спорта. 2018. № 2 (9). С. 164-173.

6. Лернер И.Я. Дидактические основы методов обучения. М.: Педагогика, 1981. 186 с.

7. Марин А.П., Пашута В.Л. Мотивация и влияние родителей на решение в выборе ребенка военного среднего образования // Актуальные проблемы физической и специальной подготовки силовых структур. № 2 (9), 2015. 110 с.

8. Матвеев А.П. Физическая культура. Рабочие программы. Предметная линия учебников А.П. Матвеева. 1-4 классы. 3-е изд. М.: Просвещение, 2014. 63 с.

9. Овсянникова О.Н. Психолого-педагогические условия развития креативных способностей у курсантов военного вуза: На материале изучения курса иностранного языка: Автореф. дис. ... канд. пед. наук. Курск, 2005. 21 с. 
10. Портнягин И.И. Научно-педагогические основы интеллектуального развития школьников-спортсменов (на материалах Республики Саха (Якутия): Автореф. дис. ... д-ра пед. наук. Якутск, 2000. 34 с.

11. Портнягин И.И. Активизация учебно-познавательной деятельности школьников в процессе физического воспитания. Якутск, 1998. 100 с.

12. Теплов Б.М. Проблемы индивидуальных различий. М.: Изд-во Акад. пед. наук РСФСР, 1961. $536 \mathrm{c.}$

13. Ашмарин Б.А., Виноградов Ю.А., Вяткина 3.Н. и др. Теория и методики физического воспитания. М.: Просвещение, 1990. 287 с.

14. Пономарев Н.И. Социальные функции физической культуры и спорта. М.: Физкультура и спорт, 1974. 310 с.

15. Виленский М.Я., Горшков А.Г. Физическая культура. 2-е изд., стер. М.: КНОРУС, 2016. $214 \mathrm{c}$.

16. Филин В.П. Воспитание физических качеств у юных спортсменов. М.: Физкультура и спорт, 1974. 232 с.

17. Филин В.П., Фомин Н.А. Основы юношеского спорта. М.: Физкультура и спорт, 1980. $254 \mathrm{c}$.

18. Холодная М.А. Психология интеллекта: парадоксы исследования. 2-е изд., перераб. и доп. СПб.: Питер, 2002. 272 с.

19. Шамаев Н.К. Нравственное развитие школьников в процессе традиционного физического воспитания. М.: Academia, 2000. 205 c.

20. Шамаев Н.К. Теория и практика нравственного развития личности подростка в процессе физического воспитания с этнокультурной направленностью: Автореф. дис. ... д-ра пед. наук. Якутск, 2000. 40 с.

21. Щукина Г.И. Проблема познавательного интереса в педагогике. М.: Педагогика, $1971.351 \mathrm{c}$.

(С Пашута В.Л., Ларькин А.И., 2021 